\title{
FLOOD ROUTING IN STEEP STREAMS
}

\author{
By \\ Chin-1ien Yen \\ Department of Civil Engineering \\ National Taiwan University \\ Taipei, Taiwan, ROC
}

\section{SYNOPSIS}

Flood routing techniques employing numerical models, especially those based on implicit finite difference schemes, have now been reasonably well accepted in practice. However, when they are applied to steep natural streams with slopes greater than 0.0005 , the problem of numerical instability often arises, resulting in break-downs of numerical models. Major factors affecting numerical stability include streem slope, cross-sectional variability, tributary confluence, boundary conditions and initial conditions. The present article reviews and summarizes some of the research results obtained by the author in recent years. Stability criteria under various influencing parameters are given, and applications to field cases in Taiwan are also illustrated in this article.

\section{INTRODUCTION}

Flood routing is a technique to determine flood hydrographs along a river reach as the flood wave travels through. This information is needed for dealing with a variety of problems, including: (i) evaluation of past flood with incomplete records, (ii) determination of flood stage for flood control scheme under design flood, (iii) forecasting of floods along a river reach, and (iv) assessment of the effects of water development project on downstream flood flow.

Basically, the flood routing technique involves solution of a set of nonlinear differential equations governing unsteady open channel flow. More than a century of research seeking methods of solution had set the stage for their applications to practical problems. This was realized when digital computers became available in 1950 's (4). However, there are still a number of difficult problems often encountered in practical application of flood routing models.

Since the initiation of using digital computer to solve the govering equations by finite difference methods for flood routing, a great number of numerical models has been developed. However, there has not yet been any single model that is far superior to others because all the finite difference schemes employed are of second-order in accuracy. Despite of this, there are overall advantages in the implicit finite difference (IFD) models (1). The IFD models are definitely faster than those employing other numerical schemes if the stream slope and Courant number are sufficiently smal1. For steep streams with Courant number in the order of unity, there is practically no choice among models. Quite often streams having rather steep slopes may lead to instability in numerical models, resulting in break-down of flood routing. The problem of numerical instability is especially serious in the case where stream slope is large and cross-sectional variability is high. Most rivers in Taiwan and maybe some of those in Japan too fall into this category. According to earlier studies $(5,6)$, channels with slopes less than 0.0005 have no problem of numerical instability. Hence, streams having slopes greater than 0.0005 are defined as steep streams in this article.

Another distinct aspect of Taiwan's rivers is their frequent tuributaries, associated with steep terrain. The junction of a tributary with its main stream brings mutual backwater effects that may place a great demand on computer resources 
and can also cause numerical instability in their solution.

The remainder of this article is devoted to the treatment of the abovementioned problems associated with flood routing in steep streams. It is hoped that this can bring some helpful suggestions to engineers and researchers as well.

\section{GOVERNING EQUATIONS}

Flood routing models may be classified into two general types; namely, process-type and lumped-type. The former takes into considerations the physical processes of water flow in river while the latter employes conceptual approach with simplified mathematical representation largely neglecting the physical processes. The following discussion is limited to the former case.

The complex phenomena of flow in natural river are generally simplified by considering the flow as one-dimensional, and the loss of energy as being properly represented by friction coefficient. With some additional assumptions (3), the governing equations, also called de Saint Venant equations, for gradually-varied open chennel flow are written as fallows:

$$
\begin{aligned}
& \frac{\partial A}{\partial t}+\frac{\partial Q}{\partial x}=0 \\
& \frac{1}{g A} \frac{\partial Q}{\partial t}+\frac{1}{2 g A^{2}} \frac{\partial}{\partial x}\left(Q^{2}\right)+\frac{1}{2 g} \frac{\partial}{\partial x}\left(\frac{Q}{A}\right)^{2}+\frac{\partial y}{\partial x}=S_{0}-S_{f}
\end{aligned}
$$

where $Q=$ discharge; $A=$ cross-sectional area ; $t=t i m e ; x=$ distance along the mean direction of flow; $g=$ gravitational acceleration; $S_{0}=$ stream bed $s$ lope; $S_{f}=$ $\mathrm{n}^{2} \mathrm{Q}^{2} /\left(\mathrm{AR}^{2 / 3}\right) ; \mathrm{y}=$ water depth; $\mathrm{n}=$ Manning's roughness; and $\mathrm{R}=$ hydraulic radius.

In the above equations, $Q$ and $y$ are the unknown variables to be sloved for. There is no general analytical solution for this system of nonlinear equations, but numerical solution may be obtained if appropriate initial and boundary conditions. are given. For the present article, the following hydrograph $Q_{1}(t)$ is imposed at the upstream boundary:

$$
Q_{1}(t)=Q_{0}+(1 / 2)\left(Q_{p}-Q_{0}\right)[1-\cos (2 \pi t / T)]
$$

where $Q_{0}=$ base flow; $T=$ duration of hydrograph; and $Q_{p}=$ peak inflow. The base flow $Q_{0}$ is also regarded as the initial condition. At the downstream boundary a depth-discharge rating curve is given by

$$
Q_{n}=a y_{n}^{b}
$$

in which $a$ and $b$ are constants for a specific site.

\section{NUMERICAL MODELS}

Numerical schemes for solving the governing equations with the boundary and initial conditions may be divided into four groups; namely, (i) finite difference schemes for characteristic equations with natural grids, (ii) finite difference schemes for characteristic equations with rectangular grid, (iii) explicit finite difference schemes for de Saint Venant equations, and (iv) implicit finite difference schemes for de Saint Venant equations. In each of these groups, a number of models have been developed for flood routing. The models in group (i) usually reguire a great deal of interpolation work to obtain results at given locations. Simplicity in computer programming tends to bring favor for models in groups (ii) and (iii), but the size of time step in these cases is severely limited by Courant condition.

Many investigators $(1,3,12)$ have shown that the models in group (iv) are the most suitable for flood routing because their stability and accuracy are genera11y better than other schemes. For slowly-varying flow with small stream slope, this is quite ture. However, for fast-varying flow with large stream slope, numerical 
stability often becomes a problem.

The discretization of Eqs. 1 and 2 by IFD scheme yields a set of simultaneous algebraic equations containing all the unknowns at all the nodal points. For this article the IFD developed by Priessmann is adopted and is given as follows $(2,3)$

$$
\left.\begin{array}{l}
f=0.5\left(f_{j+1}^{i+1}+f_{j}^{i+1}\right) \\
\frac{\partial f}{\partial t}=(0.5 / \Delta t)\left[\left(f_{j+1}^{i+1}-f_{j+1}^{i}\right)+\left(f_{j}^{i+1}-f_{j}^{i}\right)\right] \\
\frac{\partial f}{\partial x}=(1 / \Delta x)\left(f_{j+1}^{i+1}-f_{j}^{i+1}\right)
\end{array}\right\}
$$
where $\mathrm{f}=$ any varible; $i, j=$ time and spatial indices, respectively; $\Delta \mathrm{x}=\mathrm{x}_{\mathrm{j}+1}-\mathrm{x}_{\mathrm{j}}$;
and $\Delta \mathrm{t}=\mathrm{t}^{\mathrm{i}+1}-\mathrm{t}^{\mathrm{i}}$.

By substituting Eqs. 5 into Eqs. 1 and 2, and dropping the higher order terms, one can obtain two linearized equations for each subreach of the system (4):

$$
\left.\begin{array}{l}
a_{j} \Delta z_{j+1}+b_{j} \Delta Q_{j+1}=c_{j} \Delta z_{j}+d_{j} \Delta Q_{j}+e_{j} \\
a_{j}^{\prime} \Delta z_{j+1}+b_{j}^{\prime} \Delta Q_{j+1}=c_{j}^{\prime} \Delta z_{j}+d_{j}^{\prime} \Delta Q_{j}+e_{j}^{\prime}
\end{array}\right\}
$$

where $\Delta z_{j}=z_{j}^{i+1}-z_{j}^{i} ; z=$ water surface elevation $; \Delta Q_{j}=Q_{j+1}-Q_{j} ;$ and $a_{j}, \ldots e_{j}$, $a_{j}^{\prime}, \ldots$ and $e_{j}^{\prime}$ are functions of discharge and water depth at previous time. With $(\mathrm{N}-1)$ subreaches, a total of $2(\mathrm{~N}-1)$ equations are established. There are $2 \mathrm{~N}$ unknowns; namely, $\Delta z_{1}, \Delta z_{2}, \ldots \Delta z_{N}, \Delta Q_{1}, \Delta Q_{2}, \ldots \Delta Q_{N}$. Upstream and downstream boundary conditions provide two additional equations needed for the solution of $2 \mathrm{~N}$ unknowns.

\section{STABILITY CRITERIA}

The advantage of this IFD scheme is that $t$ is not subject to the strict restriction of Courant condition. Although stability analysis by linear theory shows that this scheme is unconditionally stable, numerical experiments have clear$1 y$ indicated that several factors can influence numerical stability $(2,6,7)$. A further discussion on this matter is warranted. The linear theory often fails in those situations where the stream slope, the variation of cross-section and the effects of boundary conditions are large. There has been a systematic effort in the past decade to investigate this problem, by using the technique of numerical experiments $(2,6,7,8,9,10)$. The major results of these studies are summarized in the following:

\section{Single Stream}

For a stream without any tributary, one can organize the finite difference equations and boundary conditions into dimensionless form to obtain control parameters which may be placed in the following functional relation (9)

$$
P_{x}=f_{1}\left(\Delta B_{r}, \mathbb{F}, P_{d}, P_{t}\right)
$$

where $P_{x}=S_{0} x / y_{p} ; \mathbb{F}=q_{p} / \sqrt{g y_{p}^{8}} ; P_{d}=\left|y_{b} / y_{p}-1\right| ; P_{t}=(\Delta t / \Delta x)\left(q_{p} / y_{p}\right) ; \Delta B r=\Delta B / B ;$ $\Delta B=$ variation of stream width between two neighbouring sections; $B=$ stream width, $\mathrm{S}_{\mathrm{o}}=$ stream bed slope; $\mathrm{y}_{\mathrm{p}}=$ uniform depth for $\mathrm{q}_{\mathrm{p}} ; \mathrm{q}_{\mathrm{p}}=$ peak inflow per unit width; $\Delta \mathrm{x}=$ spatial step required for numerical stability; $y_{b}=$ depth for $q_{p}$ at the downstream boundary; and $\Delta t=$ time interval.

For $\Delta t=0.25-2 \mathrm{hrs}$ covering the practical range employed for streams in Taiwan, previous investigations $(6,8,9)$ have shown that the parameter $P_{t}$ has 1 ittle 
influence on numerical stability. Therefore it is omitted. This leaves only three parameters in the function on the right hand side of Eq. 7. The stability criteria in this case are shown in Figs. 1(a) and 1(b). From these figueres, one can see that the region of numerical stability increases with decreasing $\Delta \mathrm{B}_{\mathrm{r}}$ and also with decreasing $\mathbb{F}$. The parameter $P$ has little effect on stability if $\mathbb{F}<0.9$ but it has significant effect if $\mathbb{F}>0.9$ as can be seen in Fig. 1(b) where $\mathbb{F}+P_{d}$ replaces $\mathbb{F}$ on the abscissa.
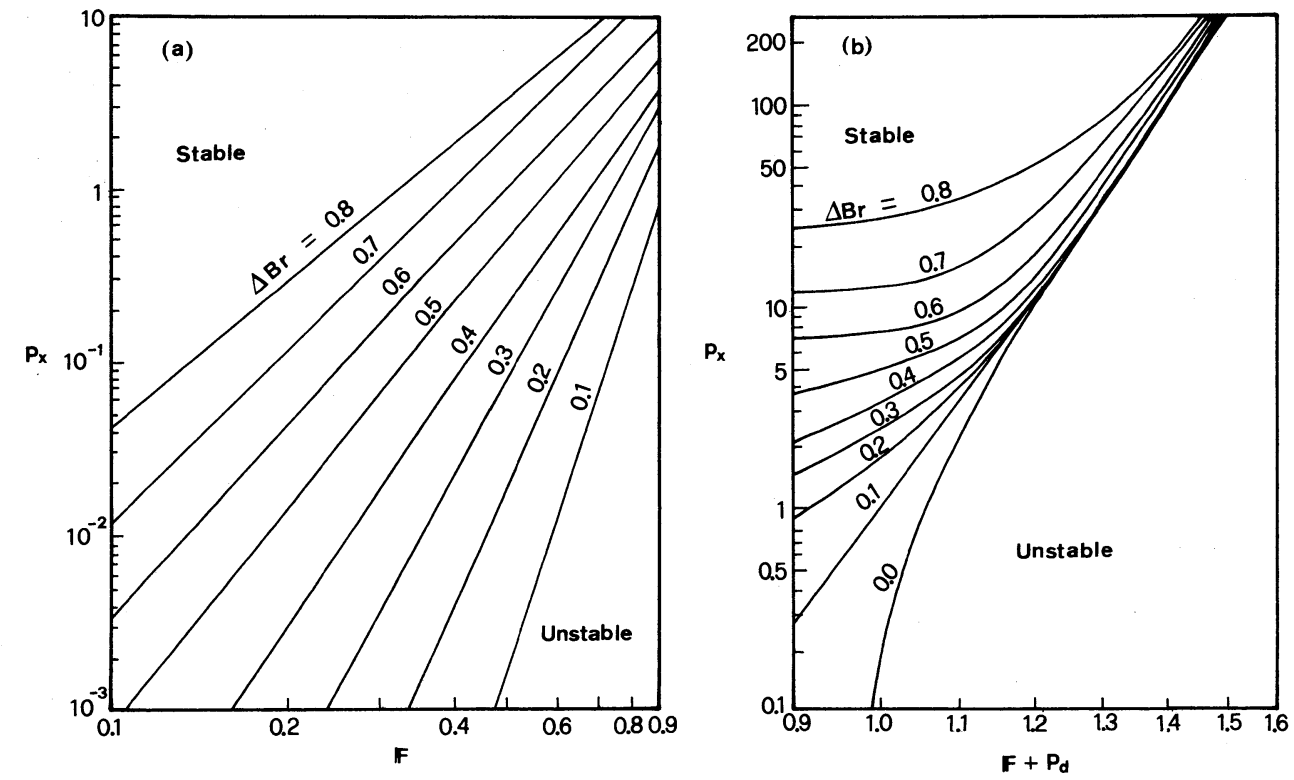

Fig. 1 Regions of stability for single stream (9)

For a given value of $\mathbb{F}$ or $\mathbb{F}+\mathrm{P}_{\mathrm{d}}$, one can choose a $\Delta \mathrm{x}$ such that $\mathrm{P}_{\mathrm{x}}$ and $\Delta \mathrm{B}_{\mathrm{r}}$ values fall onto the stable region in Fig. 1(a) or 1(b). This choice ensures that the numerical model is stable.

\section{Tributary Confluence}

When a main stream is joined by a tributary at a junction, the IFD scheme may still be applied if junction condition is properly provided. It has been found, however, that numerical instability arises if the difference in peak inflows between the main stream and the tributary is too large $(7,10)$. Investigations on the effects of tribulary carried out by using numerical experiments $(2,10)$ have shown that the stability parameter can be expressed in functional relationship as follows :

$$
\mathrm{P}_{\mathrm{x}}=\mathrm{f}_{2}\left(\mathbb{F}, \mathrm{q}_{\mathrm{pr}}, \alpha\right)
$$

where $\mathrm{q}_{\mathrm{pr}}=\mathrm{q}_{\mathrm{p} 1} / \mathrm{q}_{\mathrm{p} 2} ; \mathrm{q}_{\mathrm{p} 1}=$ peak inflow per unit width of the main stream; $\mathrm{q}_{\mathrm{p} 2}=$ peak inflow per unit width of the tributary; and $\alpha=$ time lag of the tributary peak inflow. Other parameters are the same as those defined previously. It should be noted that $\Delta B_{r}$ and $P_{d}$ are set equal to zero in these studies on the effects of $q_{p r}$ and $\alpha$. The results are shown in Fig. 2. From this figure, one can see that the region of numerical stability increases as $\mathrm{q}_{\mathrm{pr}}$ increases or as $\alpha$ decreases, but the influence of $\mathrm{q}_{\mathrm{pr}}$ is obviously greater than that of $\alpha$.

In practical application, $\mathrm{q}_{\mathrm{pr}}$ and $\alpha$ can be determined from the given upstream boundary conditions, and $\mathbb{F}$ can also be evaluated from known stream slope, roughness and inflow conditions. Upon knowing these parameters, one can choose an appropriate value of $\Delta x$ such that $P_{x}$ value will map onto the stable region in $F i g .2$. 


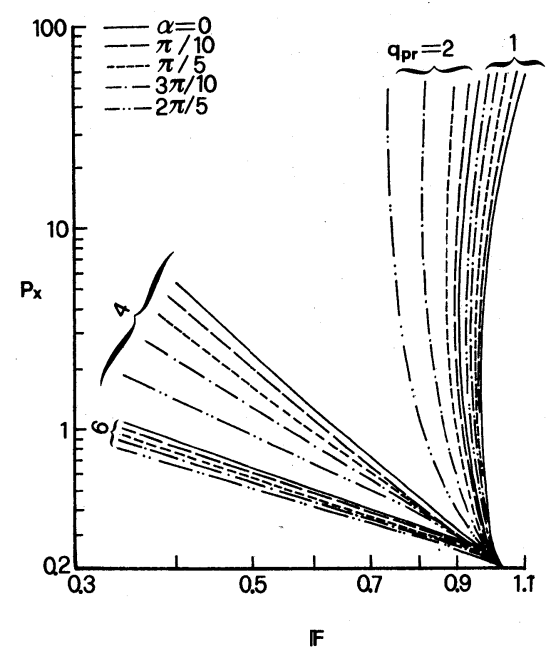

Fig. 2 Regions of stability for stream with tributary (10)

\section{Initial Condition}

From the informtion given above, it is clear that the parameter $\mathbb{F}$ plays a very important role in the criteria of numerical stability. However, this parameter $\mathbb{F}$ defined for the peak inflow, herein called peak Froude number, is different from the one for initial condition expresed as $\mathbb{F}_{6}=u_{0} / \sqrt{g y_{0}}$ where $u_{0}$ and $y_{0}$ are, respectively, the velocity and depth corresponding to the initial discharge $Q_{0}$. Numerical experiments carried out for $S_{0}=0.008-0.032$ and $\mathbb{F}=1-2$ yielded the following results (13):

$$
\frac{\sqrt{8 y_{0}}}{\Delta x / \Delta t}(1+\mathbb{F}) \geqq 0.2
$$

from which one can choose appropriate value of $\Delta x$ or $\Delta t$ to meet the stability requirements.

\section{APPLICATIONS}

The criteria presented in the last section are applied to two rivers in Taiwan. The first one is Tahan Creek which is a tributary of Tanshui River System which is composed of three major tributaries as shown in Fig. 3. The reach of Tahan Creek between Shihmen Reservoir and its confluence with the Tanshui has a total length of $35.5 \mathrm{~km}$. Its longitudinal bed profile, as shown in Fig. 4, indicates that it has a rather steep slope of about 0.045 in the upper portion (11). The variation of channe1 cross-section is shown in Fig. 5 from which one can obtain the maximum value of 0.8 for $\triangle A / A$ which is assumed to be approximately equal to $\triangle B / B$.

For $\Delta \mathrm{x}=500 \mathrm{~m}, \mathrm{~S}_{\mathrm{o}}=0.045, \mathrm{q}_{\mathrm{p}}=5 \mathrm{cms} / \mathrm{m}$ and $\mathrm{n}=0.045$, one can obtain $\mathbb{F}=0.49$ and $P_{x}=1.02$. Entering the values of the pertinent parameters into Fig. $1(a)$, one finds that the point fall onto the unstable region. When the numerical model was run with the conditions given above, it broke down and no results was obtained. At this point, one could either reduce the spatial interval $\Delta x$ or smoothen out some of the variations between the cross-sections. The latter was done in this case to bring down the maximum value of $\Delta \mathrm{B}_{\mathrm{r}}$ to be less than 0.6 and other parameters were kept unchanged. After this adjustment, numerical stability was achieved as one can find in Fig. 1(a), and the simulation model ran smoothly for the entire Tanshui River System. The results of simulation is shown in Fig. 6, indicating good agreement between the simulated and the recorded. In the simulation, the values of $\mathrm{q}_{\mathrm{pr}}, \alpha$ and $\mathbb{F}_{\mathrm{o}}$ are all within the range of stability under given $\mathbb{F}$ and $\mathrm{P}_{\mathrm{x}} \cdot$ The 
same model has also been sucessfully applied in other studies $(14,15)$.

A similar test has also been carried out for Tsengwen River in southern Taiwan (16). The values of variables used are : $\Delta x=600 \mathrm{~m}, \Delta \mathrm{A} / \mathrm{A}=0.5, \mathrm{~S}_{0}=0.035, \mathrm{q}_{\mathrm{p}}=$ $6 \mathrm{cms} / \mathrm{m}$ and $\mathrm{n}=0.040$. These values yield $\mathbb{F}=0.55$ and $\mathrm{P}_{\mathrm{x}}=0.91$. From Fig. 1(a), one then finds that numerical stability can be achieved, and again the simulation model has been run without any trouble. However, when n-value was changed to 0.03 , then $\mathbb{F}=0.7$ and $P_{x}+\mathbb{F}=1.08$ were obtained. This resulted in numerical instability, both from Fig. 1 and from running the simulation model. Once again the criteria for stability were verified.

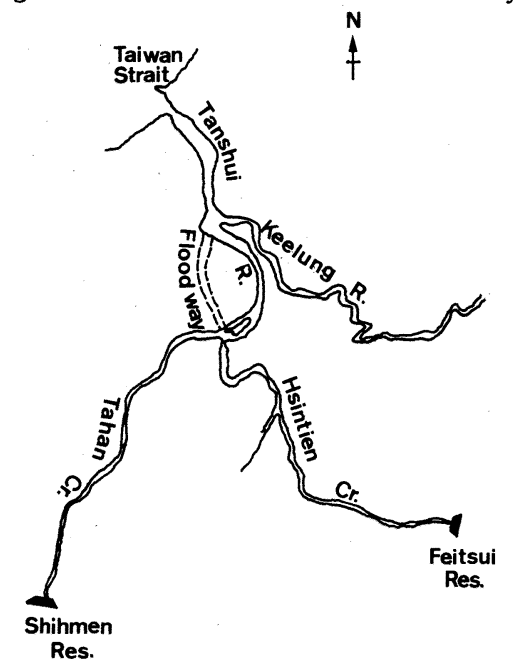

Fig. 3 Tanshui River System (11)

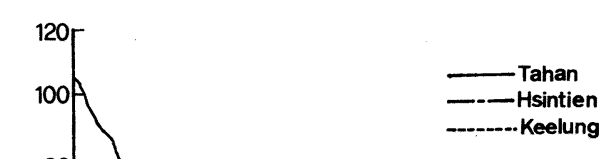

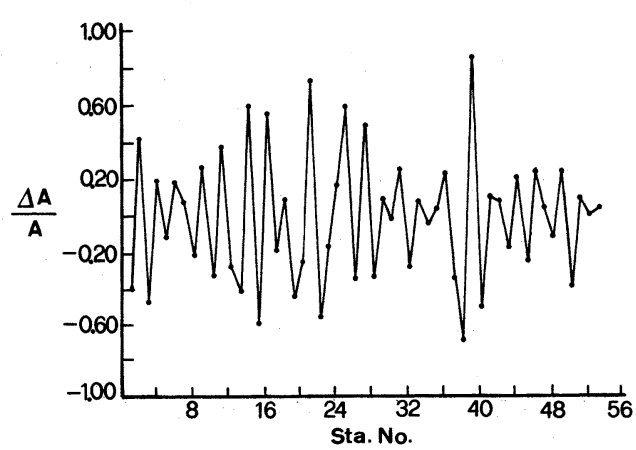

Fig. 5 Variation of $\Delta \mathrm{A} / \mathrm{A}$ in Tahan Cr. (2)
Fig. 4 Bed profiles of Tanshui River System (11)

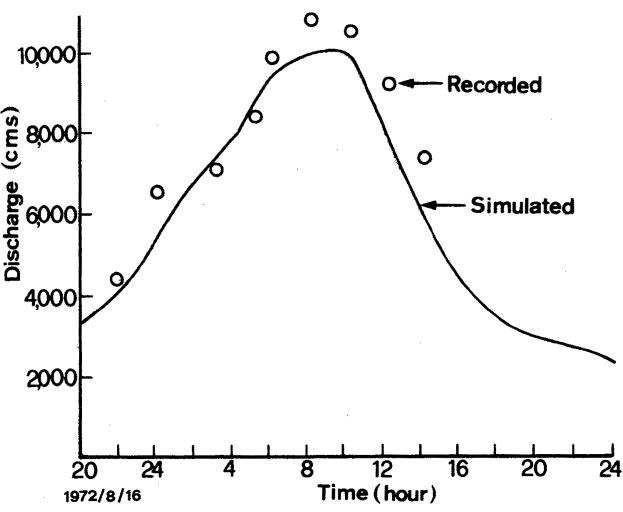

Fig. 6 Hydrograph at Taipei Bridge

\section{CONCLUSIONS}

On the basis of the results of recent researches on flood routing for steep streams as reviewed and summarized above, one can draw following conclusions:

1. Fully implicit finite difference models for flood routing is unconditionally stable only if the stream slope is small enough. In addition, cross-sectional variability, tributary contluence, boundary conditions and initial 
conditions also have significant influences on numerical stability when the stream slope is greater than 0.0005 . The time interval of routing $(\Delta t)$ has little influence when $\Delta t$ is in the range of $0.5-2.0 \mathrm{hrs}$.

2. Numerical exeriments have shown that the stability parameter $P_{x}$ for single channel is a function of the peak inflow Froude number $\mathbb{F}$, ratio of cross-sectional variation $\Delta B_{r}$ and the parameter of downstream rating curve $P_{d}$, as shown in Fig. 1 .

3. For streams with tributary confluence, two more parameters, the ratio of peak inflow $\mathrm{q}_{\mathrm{pr}}$ and the time lag between inflows $\alpha$, must be taken into consideration in the determination of $\mathrm{P}_{\mathrm{x}}$. The effects of $\mathrm{q}_{\mathrm{pr}}$ and $\alpha$ are shown in Fig. 2.

4. When the initial flow condition is supercritical the initial Froude number $\mathbb{F}_{0}$ plays an important role in numerical stability. Its influence on stability is given in $\mathrm{Eq} .9$.

5. Although the stability criteria for flood routing in steep streams developed so far have been tested with a few cases of Taiwan's streams and have shown quite good agreement, further tests under various field situations are still recommended.

\section{REFERENCES}

1. Amein, A.O. and C.S. Fang : Implicit flood routing in natural channels, Proc. ASCE Journal of the Hydraulics Division, ASCE, Vo1.96, HY12, pp.2481-2500, 1970 .

2. Hsu, M.H. : Stability of nonlinear implicit model for unsteady flow in $\mathrm{Ri}$ vers, Disseration submitted in partial fulfilment of the requirements for the degree of Doctor of Engineering in the Department of Civil Engineering, National Taiwan University, Taipei, 1984.

3. Mahmood, K. and V. Yevjevich ed. : Unsteady Flow in Open Channe1s, Vo1.1, Water Resources Publications, Fort Collins, Colorado, 1975.

4. Stoker, J.J. : Numerical solution of flood prediction and river regulation problems - (i) derivation of basic theory and formalation of numerical methods of attack) Report, New York University Institute of Mathematical Sciences, No. IMM-200, 1953.

5. Yen, C.L. and H.F. Tsai : Influence of cross-section irregularities on stability of numerical solution of unsteady flow, Research Report, Department of Civil Egineering, National Taiwan University, No.HY6901, 1980 (in Chinese).

6. Yen, C.L. : Influence of channel slope on numerical stability in unsteady flow simulation, Proceedings of the 7th Australasian Hydraulics and Fluid Mechanics Conference, pp.484-487, 1980.

7. Yen. C.L. and M.H. Hsu : A numerical model for unsteady flow in river system, Proceeding of the 3rd Congress, IAHR-APD, pp.91-101, 1982.

8. Yen, C.L., M.H. Hsu and Y.S. Ko : Influence of boundary conditions on stability of numerical solution of unsteady flow, Research Report, Deptartment of Civil Engineering, National Taiwan University, No.HY7201, 1983 (in Chinese).

9. Yen, C.L. and M.H. Hsu : Numerical stability of unsteady flow simulation in open channel, Proceedings of the 4th Congress, IAHR-APD, pp.815-829, 1984.

10. Yen, C.L. and M.H. Hsu : Numerical stability of unsteady flow simulation in river with tributary, Proceedings of the $4 \mathrm{th}$ International Conference on Applied Numerical Modeling, pp.387-390, 1984.

11. Yen, C.L., M.H. Hsu and C.C. Tang : Flood routing models for Tanshui River System - (iii) routing in conjunction with runoff models, Research Report, National Science Council, ROC, No.DPR74-26, 1985 (in Chinese).

12. Yen, C.L. : An overview on flood routing, Proceedings of the ROC-Japan Joint Seminar on Mutiple Hazards Mitigation, pp.559-582, 1985.

13. Yen, C.L. and C.H. Lin : Numerical stability in unsteady supercritical flow simulation, Proceedings of the 5th Congress, IAHR-APD, pp.29-44, 1986.

14. Yen, C.L. : Flood forecasting system in Tanshui River Basin, Proceeding of the US-Asia Conference on Engineering for Mitigating Natural Hazards Damage, pp.B4/1-12, 1987.

15. Yen, C.L. and C.F. Liu : Flood routing models for Tanshui River System - (v) influence of reservoir operations on floods, Research Report, National Science 
Counci1, ROC, No.DPR76-51, 1988 (in Chinese).

16. Hsu, M.H., R.Y. Wang and C.L. Yen : A flood routing model for river with over levee flows and its applications, Journal of Chinese Agricultural Engineering, Vol.34, pp1-11, 1988 (in Chinese).

\section{APPENDIX - NOTATION}

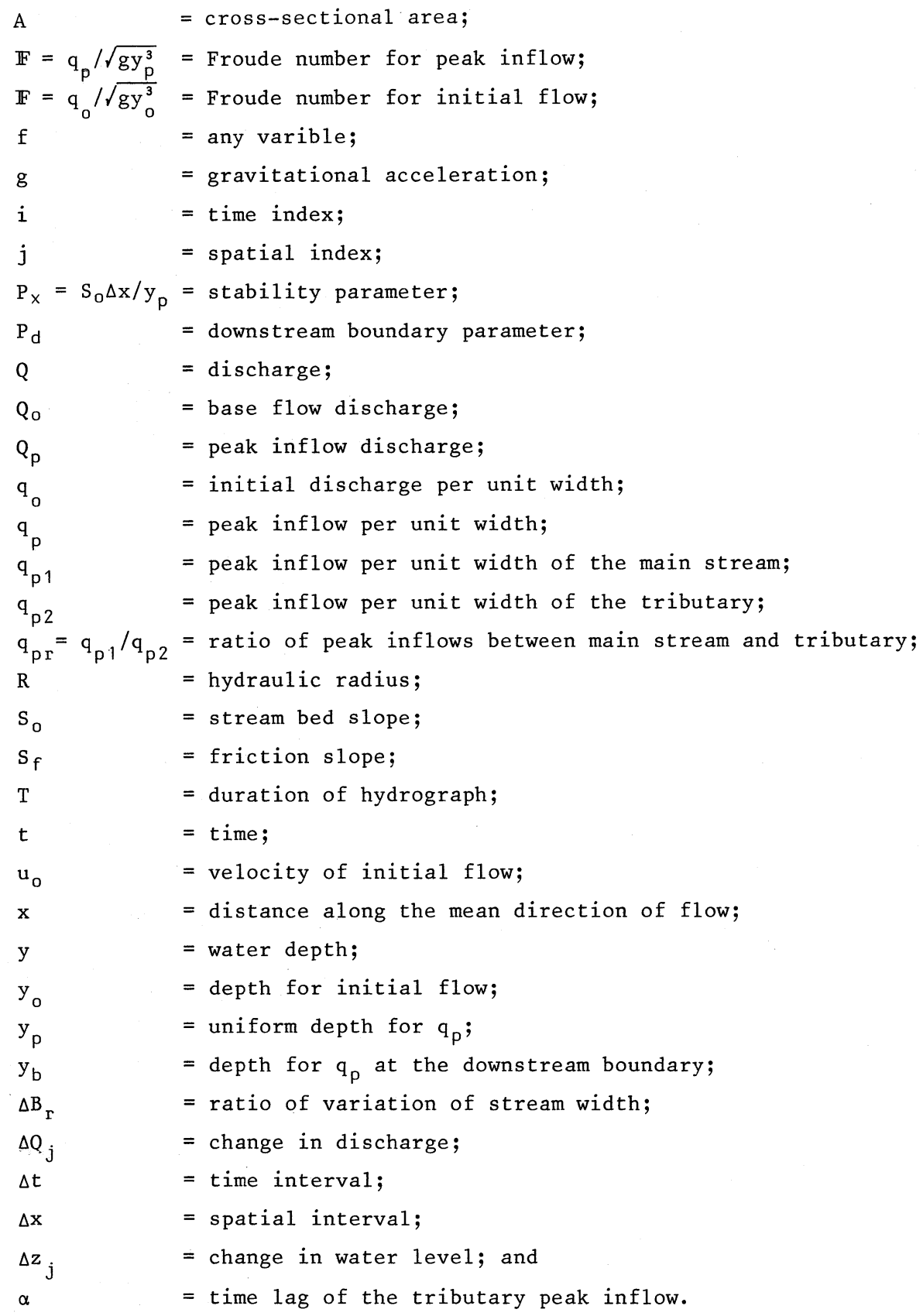

